\title{
Discursividades sobre o bibliotecário
}

Gustavo Grandini Bastos

\begin{abstract}
Mestrando em Ciência, Tecnologia e Sociedade no Centro de Educação e Ciências Humanas da UFSCar. Bolsista CAPES. Pesquisador no E-L@DIS - Laboratório Discursivo: sujeito, rede eletrônica e sentidos em movimentos
\end{abstract}

Fernanda Correa Silveira Galli

Pós-doutoranda no Departamento de Educação, Informação e Comunicação (DEDIC) da FFCLRP/USP. Bolsista FAPESP.Pesquisadora no EL@DIS - Laboratório Discursivo: sujeito, rede eletrônica e sentidos em movimentos (FAPESP)

Lucília Maria Sousa Romão

Livre-Docente em Ciências da Informação e da Documentação pela Universidade de São Paulo. Professora do Curso de Graduação em Ciências da Informação e da Documentação e do Programa de Pós-Graduação em Psicologia, ambos da FFCLRP/USP. Professora colaboradora do Programa de Pós-Graduação em Ciência, Tecnologia e Sociedade da UFSCar. Coordenadora do E-L@DIS - Laboratório Discursivo: sujeitos, rede eletrônica e sentidos em movimento (FAPESP).Bolsista CNPq

Nosso objetivo, neste artigo, é pensar as discursividades que circulam sobre o bibliotecário, nos espaços denominados bibliotecas comunitárias, instituições informacionais de grande relevância cultural e social, que, muitas vezes, não contêm esse profissional no quadro de funcionários. Em nossas reflexões, temos o intuito de: i) apresentar uma breve discussão conceitual sobre essas bibliotecas, organizações que permitem inscrições discursivas tão particulares, principalmente em locais muito carentes de apoio informacional; e ii) realizar um trabalho de escuta dos sentidos que são discursivizados acerca do profissional bibliotecário, com base nos conceitos da análise do discurso (AD) de filiação pecheuxtiana.

Palavras-chave: Discursividades; Bibliotecário; Biblioteca Comunitária. 


\section{Discourses on the librarian}

In this paper, think about the discourses that circulate in the space called the librarian community libraries, institutions of great informational social and cultural relevance, often don't contain this professional staff. In our reflections, we have the aim of: i) provide a brief conceptual discussion about these libraries, organizations that provide such specific discursive inscriptions, especially in very poor informational support, ii) perform a job of listening to the meanings that are concerning discourse professional librarian, based on the concepts of the French Discourse Analysis.

Keywords: Discursivity; Librarian; Community Library.

Recebido em 03.04.2012 Aceito em 08.02.1013

O homem, o bibliotecário imperfeito, pode ser obra da sorte [...] (BORGES, 1975, p. 81)

[...] cada exemplar é único, insubstituível, mas (como a Biblioteca é total) há sempre várias centenas de milhares de fac-símiles imperfeitos: de obras que apenas diferem por uma letra ou por uma vírgula (BORGES, 1975, p. 85-86).

\section{Um começo...}

A biblioteca não é apenas o lugar do bibliotecário. Uma infinidade de outros profissionais tem atuado e desenvolvido atividades nesse espaço informacional, principalmente nas instituições comunitárias, que são o foco deste escrito. Como analistas do discurso, pensar sobre os dizeres que os sujeitos que atuam nessas bibliotecas enunciam é algo que nos parece relevante. Mais especificamente, nosso intuito é compreender e ouvir que sentidos acerca do profissional bibliotecário circulam no bojo do discurso dos agentes que atuam nesses espaços informacionais das suas comunidades, muitas vezes espaços sociais que nunca contaram com o apoio de um órgão informacional.

Nosso interesse investigativo, então, repousa sob as bibliotecas comunitárias, instituições formadas e mantidas a partir do desejo de sujeitos de determinadas comunidades, os quais contribuem na construção e constituição desses espaços informacionais. O que nos parece relevante, também, é que muitos desses espaços não contam com bibliotecários no quadro de funcionários, mas, mesmo assim, realizam 
trabalhos que têm gerado grande impacto nas comunidades em que estão inseridos. Nesse sentido, com base nas contribuições da análise do discurso de filiação pecheuxtiana, observamos, em recortes de entrevistas ${ }^{1}$, marcas que apontam a atuação do bibliotecário nas instituições comunitárias.

Destacamos que as entrevistas foram realizadas por meio da ferramenta eletrônica e-mail, entre os dias 4 de maio de 2010 e o dia 20 de agosto de 2010. A seleção das bibliotecas para coleta das entrevistas teve como base dois critérios principais: i) instituições consolidadas e que, durante nossa busca, chamaram a atenção pela relevância e forma de atuação nas comunidades em que se encontram inseridas; e ii) bibliotecas que se encontrassem localizadas em diferentes partes do país. Selecionamos, assim: a Biblioteca Comunitária Maria das Neves Prado (Bahia, Nordeste do país); a Sociedade Amantes da Leitura: Biblioteca Barca dos Livros (Santa Catarina, Sul do país); e a Biblioteca BECEI de Paraisópolis (São Paulo, Sudeste do país).

Para as discussões neste artigo, trazemos apenas três recortes ${ }^{2}$ um de cada biblioteca - acerca da questão: Como você imagina o trabalho e o discurso do bibliotecário ou do profissional que cuida da biblioteca? Antes de partimos para o processo de análise de nosso corpus, tecemos considerações sobre a perspectiva teórica adotada - a análise do discurso pecheuxtiana.

\section{Referencial discursivo: alguns conceitos}

Utilizamos, como base referencial de nosso estudo, a análise do discurso de filiação pecheuxtiana e apontamos, de início, o seu processo de estabelecimento como uma teoria conceitual que atravessou um período de difícil estruturação e que demandou um trabalho árduo de uma série de pesquisadores. A constituição teórica da análise do discurso se dá no final dos anos 60, época em que a corrente de pensamento Estruturalista apresentava-se como o marco conceitual e intelectual da época (ORLANDI, 2003), sendo um período assinalado pela constante exclusão do sujeito como figura relevante durante a análise e reflexão do/no fazer científico, de modo que "importava normalizar o sujeito, já que era visto como o elemento suscetível de perturbar a análise do objeto científico, que deveria corresponder a uma língua objetivada, padronizada" (FERREIRA, 2010, p. 19).

A ilusão do controle, da neutralidade, afetava como nunca a ideia de fazer Ciência; contudo, após as relevantes mudanças históricossociais, pelas quais a sociedade francesa atravessou no período posterior ao Maio de 1968, foi impossível continuar tentando ocultar o sujeito dos estudos acadêmicos (FERREIRA, 2003). A análise do discurso teve uma dupla marca de fundação (MALDIDIER, 1997), através das contribuições de Michel Pêcheux, com o lançamento de seu livro intitulado Análise

\footnotetext{
${ }^{1}$ Composta por 13 questões.

${ }^{2}$ Uma abordagem mais ampla, de outros recortes da pesquisa, pode ser encontrada em BASTOS (2010).
} 
Automática do Discurso e o lançamento da Revista Langages, publicada sob a organização de Jean Dubois (FERREIRA, 2003).

A AD caracteriza-se, como se vê, desde o seu início, por um viés de ruptura a toda uma conjuntura política e epistemológica e pela necessidade de articulação a outras áreas das ciências humanas, especialmente a lingüística, o materialismo histórico e a psicanálise (FERREIRA, 2003, p. 41).

Escapando de uma visão meramente categorizadora ou que identifica a linguagem como um lugar de clareza, a AD trabalha com a ruptura. Temos, no discurso, um objeto que não é apenas linguístico, mas, também, sócio-histórico, sendo, portanto efeito de sentido entre os sujeitos envolvidos na interlocução. A evidência, pretensa clareza ou intencionalidade do dizer se torna impossível, pois a ambiguidade afeta o discurso e a língua; desse modo, não é possível pretender uma clareza ou comunicação sem falhas, visto que ela inexiste em um processo comunicacional (ORLANDI, 2005). É no discurso que observamos os movimentos que afetam os processos de significação que afetam o sujeito, a história e a língua (FERREIRA, 2003; ORLANDI, 2005).

O discurso é um campo fecundo de estudos da linguagem, o que estabelece um distanciamento da linha comunicacional clássica tão difundida e composta pelos elementos: emissor, receptor, código, referente e mensagem. Essa ideia da comunicação como uma mera troca informacional, baseada em um processo seriado e simplista, não se aplica nos processos de reflexões da $A D$, principalmente pelo fato de que não tomamos a mensagem como objeto central de análise, mas, sim, o discurso. Temos sentidos e sujeitos envolvidos no processo de enunciação e, por consequência, eles são afetados pela história e pela língua, o que resulta em uma relação muito mais complexa do que uma mera troca informacional, em que um sujeito e um sentido são afetados durante a comunicação (ORLANDI, 2009).

A linguagem serve para comunicar e para não comunicar. As relações de linguagem são relações de sujeitos e de sentidos e seus efeitos são múltiplos e variados. Dai a definição de discurso: o discurso é efeito de sentidos entre locutores (ORLANDI, 2009, p. 21).

Um ponto que marca a $A D$ é o sujeito como uma posição que é produzida no processo histórico e linguístico, afetado pelo processo conflituoso, contraditório e conturbado, fruto da tensão fomentada no seio da ideologia, social e história (MARIANI, 2003). O sujeito a que estamos nos referindo ocupa uma posição social e ideológica em um determinado momento histórico, e posteriormente pode não mais ocupar, ou seja, a instabilidade e o conflito marcam e constituem o sujeito na perspectiva 
discursiva. Nesse sentido, as 'escolhas' realizadas pelo sujeito não são aleatórias, mas frutos de um processo ideológico, no qual ele crê que determinado sentido é o mais 'correto' de ser enunciado e, assim, a ideologia é produzida "justamente no ponto de encontro da materialidade da língua com a materialidade da história" (ORLANDI, 1997, p. 20).

Para a $A D$, a ideologia não é o sistema que obscurece a visão de quem olha, ocultando um ponto de vista, mas uma ponte de relação entre o sujeito e a exterioridade, de modo que um dizer acaba por fazer sentido ou não para o sujeito. A sensação de evidência que afeta o sujeito no momento da enunciação é o que possibilita que seu dizer tenha significação no contexto sócio-histórico que ele se insere (ORLANDI, 1997) e acabe, assim, fazendo sentido para os demais sujeitos. Isso é o que permite que o sujeito tome a palavra, movimentando-se pela língua, enunciando regularidades e trazendo à tona já-ditos, que são acionados em outro momento e fazem emergir sentidos outros, em outros lugares.

É através da ideologia que o sujeito crê na ilusória transparência da linguagem e tece seu dizer. O sujeito e o sentido são constituídos no discurso, afetados e articulados pela ideologia (ZOPPI-FONTANA, 2005). A ideologia articula a ilusão da crença da literalidade, já que as palavras não se encontram pregadas aos sentidos. O momento discursivo, desse modo, sempre se encontra exposto ao erro, a falha, ao ruído, visto que o sentido não tem um lugar assegurado na história, o que também impede a garantia da certeza no encontro discursivo (ORLANDI, 2005).

O sujeito, ao enunciar, toma como suas palavras outras e apropriase de uma memória (já-ditos) que pode se manifestar de diferentes maneiras, dada a heterogeneidade que o constitui. De acordo com Orlandi (2005), baseada em pressupostos estabelecidos por Pêcheux, não temos uma separação da linguagem e da história, elas estão relacionadas, de modo que o saber discursivo possibilita a retomada de estruturas préconstruídas que vão afetar a forma como o sujeito irá realizar o processo de significação, em outro lugar, de forma independente (ORLANDI, 2003, 2005), já que:

[...] para que nossas palavras façam sentido, é preciso que elas já tenham sido ditas e reditas em outros contextos sócio-históricos em uma espiral da qual não se tem o inicio nem o fim e, dessa forma, a qual não se pode classificar, ordenar, sistematizar e alocar com precisão. Pode-se rastrear as relações entre os significantes e os contextos de produção de sentido, pode-se mapear os deslocamentos de sentidos percorridos por zonas dessa memória, buscando interpretar a língua em funcionamento e tatear o quanto se tem ilusão de poder (PACÍFICO; ROMÃO, 2006, p. 7).

É, então, via formação discursiva - que engendra o que pode e deve ser dito a partir do lugar que o sujeito ocupa e do modo como ele é capturado pela ideologia - que o sujeito enuncia e passa por um processo 
constante de resistência. Contudo, é nesse entremeio que o sujeito tem a possibilidade de resignificar sentidos, pois a resistência é a busca de um espaço para enunciar o que acabou sendo silenciado no discurso, e que se manifesta por meio do lapso, da falha, do equívoco. Durante sua enunciação e interpretação (ORLANDI, 2003), o sujeito acaba por filiar-se a determinados sentidos e formações discursivas que são constituídas por uma série de fatores exteriores, que escapam de sua dominância, alterando colocações, formulações e sentidos.

As movimentações na teia discursiva permitem filiações e deslocamentos constantes do sujeito, já que a posição que ele ocupa no discurso se altera, desliza. São esses deslizamentos de posições e de sentidos que nos interessam observar nas discursividades sobre 0 bibliotecário.

\section{Bibliotecas comunitárias: discursividades sobre o bibliotecário}

Alguns relatos (cf. BASTOS, 2010; BASTOS; ALMEIDA; ROMÃO, 2011) marcam a biblioteca e a informação como importantes motores de desenvolvimento social, um verdadeiro insumo necessário para o crescimento comunitário, afetando efetivamente os sujeitos que ali vivem. Na literatura da Ciência da Informação, essas bibliotecas são conceituadas de formas diferentes em nações desenvolvidas e nas que se encontram em processo de desenvolvimento. Destacamos que, neste trabalho, atentamos apenas para as instituições desenvolvidas no Brasil, e focamos a noção de biblioteca comunitária existente em nações em desenvolvimento, ou seja, aquelas que existem e realizam ações em comunidades que antes passavam por alguma problemática no acesso às ações culturais, informacionais e de leitura (MACHADO, 2008), o que, no Brasil, não é uma exceção, visto que ainda é um país com sérios problemas sociais e que possui uma relação complexa com as bibliotecas e com a leitura (INSTITUTO PRÓ-LIVRO, 2008; BASTOS, 2010).

O processo de constituição dessas instituições também nos desvela uma biblioteca diferente, que é constituída pela própria vontade daquela comunidade. A biblioteca não é apenas aberta e colocada ali, ela é desejada, forjada com as forças daquela comunidade, seja através de um pensar coletivo, de um sujeito que faz parte dela ou alguém que está fora dela. Assim, a biblioteca comunitária se constitui e passa a integrar o pensar daqueles sujeitos de maneira efetiva. Como já dito anteriormente, é uma relação diferente das estabelecidas com outras tipologias de biblioteca.

Historicamente, a biblioteca tem sido um espaço de restrição, desde a Antiguidade, quando os prédios eram vigiados, construídos de forma a impedir a circulação das obras ali encontradas, visto que seu acesso era autorizado a um grupo restrito (SANTOS, 2010). Atualmente, as bibliotecas são diferentes, houve mudanças de suporte, estrutura, organização e possibilidades de difusão informacional. No entanto, em nosso país, permanece uma série de complicadores que acabam afastando 
possíveis leitores de realizar uma aproximação com esse espaço, o que reflete na dificuldade de fomentação de leitores (LAJOLO; ZILBERMAN, 2003; INSTITUTO PRÓ-LIVRO, 2008). Assim, a restrição que afeta o sujeito contemporâneo brasileiro é de outra ordem: a falta, tanto no que tange à diversidade dos acervos quanto de instituições, além dos horários que pouco favorecem muitos dos brasileiros (LAJOLO; ZILBERMAN, 2003; INSTITUTO PRÓ-LIVRO, 2008).

É nessa falta que as bibliotecas comunitárias se constituem, principalmente em locais periféricos, com uma infinidade de problemas sociais que necessitam de amparo e onde a ausência de instituições culturais - como as bibliotecas e centros de informação - permanecem, muitas vezes, como espaços tão distantes da realidade ali vivenciada. A partir dessas considerações, buscamos flagrar como esse profissional é marcado discursivamente nessas instituições, já que muitas vezes elas não contam com esse profissional. Segundo Milano e Davok (2009), o bibliotecário é compreendido como o profissional da informação, tendo sua atuação ampliada com as alterações sociais, econômicas e tecnológicas que o mundo vem atravessando.

As possibilidades de atuação do bibliotecário nas bibliotecas comunitárias e a relevância desse profissional da informação, como um insumo indispensável para o desenvolvimento das mais variadas atividades, ainda têm pouca visibilidade (MILANO; DAVOK, 2009). Em nosso processo de análise, selecionamos três recortes de entrevistas realizadas com profissionais de três instituições comunitárias de diferentes regiões do país, que possuem formas de trabalho distintas e que apresentam destaque nas regiões que atuam. No primeiro recorte, observamos a problematização do profissional da informação:

(...) deve atentar à qualidade de leitura, procurando envolverse com os leitores, principalmente com as crianças, para melhor atende-los e garantir o aproveitamento das leituras, para incentivar e formar leitores. O bibliotecário deve ser simpático e solícito, ter as características de um bibliotecário de referência, para ganhar a confiança dos leitores, indicando a eles, sempre que possível, o que é, mais do que do agrado deles, mas, aquilo que os fará crescer como leitores (Representante da Biblioteca Comunitária "Barca dos Livros Sociedade Amantes da Leitura").

Temos, no primeiro recorte, a marca de uma profissão que requer uma lista de predicados para que possa ser exercida: os adjetivos 'simpático' e 'solícito' - trazem esse discurso que atribui ao profissional a capacidade de realizar as tarefas que a posição de um 'bibliotecário de referência' implica. Ocorre uma apresentação do bibliotecário como o profissional que 'incentiva', 'forma' e 'envolve' os sujeitos e 'garante o aproveitamento da leitura', traços que colocam esse sujeito numa posição de guia, de referência, um profissional capaz de permitir que os leitores se 
interessem fortemente pela leitura, a ponto de migrarem da posição de não-leitores para a de leitores. Destacamos que essa marca do bibliotecário, como o orientador da leitura ou formador de leitores é antiga, ela vem de uma concepção da Antiguidade, principalmente do período Medieval, quando o bibliotecário era autorizado a adentrar os labirintos da instituição, sendo conhecedor de sua estrutura, entradas e saídas. Ele autorizava a leitura ou não de determinadas obras e tinha, de certa forma, o poder sobre a informação. Essa posição do bibliotecário como guia carrega marcas naturalizadas pela ideologia que aponta essa visão como correta.

Observamos que, juntamente com essa concepção do bibliotecário como o sujeito que orienta, temos uma rede sentidos que discursiviza o profissional como aquele que sabe o que deve e o que é digno de ser acessado e usado pelos leitores. Como já dissemos, a leitura é envolta, também, de predicados de eficiência e importância dentro de nossa sociedade: a palavra escrita, para ser lida, sempre teve grande relevância, uma das marcas disso foi deixada pelos portugueses no Brasil, o que podia ser lido era (é) tomado como legítimo e digno de ser observado como prova, ou seja, o que era e é escrito ocupa uma posição de maior legitimidade frente ao que é falado.

Essa marcação de quem sabe o que indicar apresenta um profissional que precisa não apenas conhecer o que se deve ler, mas pode levar os leitores a terem acesso àquilo 'que os fará crescer'. Temos, nessa sequência, uma inscrição que parece revelar um profissional capaz de antever o que o leitor não apenas deseja, mas necessita, um oráculo que se aproxima do que os meios de informação e comunicação oferecem e/ou prometem por meio dos recursos tecnológicos. Observamos que 0 substantivo 'confiança' indica uma relação de proximidade entre as posições de sujeito-leitor e de sujeito-bibliotecário, nos remetendo a uma ideia quase mercantil de troca entre ambos.

Vejamos agora o segundo recorte:

Não sou bibliotecário formado, também não é meu desejo de ser um más me considero um verdadeiro bibliófilo, pois gosto muito de estar no meio dos livros, por isso me sinto uma pessoa inteligente e sei conversar e é assim que imagino um bibliotecário, inteligente e paciente (Representante da Biblioteca Comunitária "BECEI de Paraisópolis").

Marcamos, nesses dizeres, o aparecimento de outra formação discursiva sobre o profissional que atua na biblioteca, mas não é bibliotecário, o que é bastante comum em nosso país (ALMEIDA; MACHADO, 2006; MACHADO, 2008), e o que, também, foi observado em nossa pesquisa, visto que das bibliotecas selecionadas apenas uma (a Sociedade Amantes da Leitura: Biblioteca Barca dos Livros) conta com bibliotecários, as outras duas (BECEI de Paraisópolis e Comunitária Maria das Neves Prado) realizam suas atividades com o apoio de profissionais que não têm essa formação. Observamos, assim, um sujeito que, embora atue na 
biblioteca, assinala não ser um bibliotecário, e sim um 'bibliófilo' - o que faz emergir uma diferença não só de posição, como também de condição.

Colocando-se na posição daquele "que tem amor aos livros, especialmente os belos e raros" (MICHAELIS..., 2009), o profissional também se vê como alguém que tem mais prestígio que um bibliotecário, ao enunciar: 'me sinto uma pessoa inteligente e sei conversar e é assim que imagino um bibliotecário'. Com esse discurso que the concede o status de conhecedor dos livros e de sabedor do trabalho com a leitura, o sujeito manifesta que não está naquele espaço por obrigação - como muito se observa, por exemplo, no discurso de profissionais readaptados das bibliotecas escolares -, mas porque gosta 'muito de estar no meio dos livros' e deseja estar em atividade na biblioteca.

Nossa observação recai sobre o fato de que se instaura outra forma de dizer sobre o profissional que atua nas instituições comunitárias: ocorre um deslizamento de sentido sobre quem atua na biblioteca, já que evidenciamos que não apenas o bibliotecário desenvolve atividades nesses espaços, mas muitos outros profissionais, inclusive os que não possuem diploma de bibliotecários. Temos, ainda, outra região de sentidos: os que gostam da biblioteca e de atuar com questões referentes à leitura encontram seu espaço. Há, novamente, a repetição de adjetivos ('inteligente e paciente') que qualificam o sujeito-bibliotecário, além do efeito de antecipação - 'imagino' - que coloca em curso, pela memória discursiva, como o profissional é imaginarizado. Para ocupar essa posição, então, ele deve preencher tais requisitos.

No recorte que segue, temos, também, a emergência do discurso de um profissional que parece se constituir a margem, dado que sua formação não atende à burocratização da profissão - pelo diploma ou outro processo normatizador. Vejamos:

Esta pergunta tem dois aspectos: um é quanto ao discurso do bibliotecário ou do profissional envolvido com a(s) biblioteca(s) oficial(ais), o outro é o discurso desses mesmos profissionais envolvidos com a biblioteca comunitária. Já a segunda categoria, a biblioteca comunitária o discurso muda radicalmente, Primeiro porque esta categoria de biblioteca não exige uma formação especifica de bibliotecário formado e com registro no seu respectivo órgão de classe. Da mesma forma, a biblioteca comunitária não é organizada para gerar emprego desta ordem, ou seja, ela pode gerar emprego sim e deve gerar, mas o profissional que nela vai trabalhar (pode ser até um bibliotecários com todos os requisitos exigidos pelas outras categorias de bibliotecas) não tem esse caráter corporativo. Calcula-se que mais de $80 \%$ das pessoas que estão envolvidas com bibliotecas comunitárias não têm diploma de ensino superior, no máximo o do segundo grau. Aliás, é muito comum encontrar excelentes lideranças no movimento de bibliotecas comunitárias que são analfabetas e defendem a importância 
de ter neste tipo de organização programas de leitura, contadores de história, formação política etc. Claro que se o total de militantes do movimento de bibliotecas comunitárias tivesse um curso superior o nível de leitura iria ser muito mais avançado (Representante da Biblioteca Comunitária "Maria das Neves Prado").

O sujeito, nesse terceiro recorte, nos remete a uma memória sobre a existência de duas posições discursivas possíveis de serem enunciadas, ao falar de duas possibilidades quando se refere acerca de qual profissional atua na biblioteca: i) na primeira, temos o sujeito com diploma, oficializado e compreendido como o bibliotecário das instituições nomeadas como 'bibliotecas oficiais'; e ii) na segunda, os profissionais que atuam sem diploma ou vínculo de classe com os bibliotecários, assumindo uma posição de marginalidade, lado a lado nessas bibliotecas comunitárias (como visto no recorte anterior, que trouxe a nomeação de bibliófilo para a descrição).

$\mathrm{Na}$ primeira sequência discursiva, observamos concepções que marcam o bibliotecário como um funcionário que se submete/ajusta às regras que a instituição em que trabalha exige, o que evoca um imaginário de profissional focado/ligado com a questão da normatização, a parte nomeada. Já na segunda, temos a abordagem dos profissionais que atuam nas bibliotecas comunitárias: há marcas que apontam para outra posição, a não burocratizada através do diploma e outras formas de regularização, quando considera que 'esta categoria de biblioteca não exige uma formação especifica de bibliotecário formado e com registro no seu respectivo órgão de classe'. Vemos, ainda nessa segunda sequência discursiva, uma abertura de espaço para abordar esse sujeito que atua nessas bibliotecas e não é um bibliotecário.

Observamos que emerge uma nova possibilidade de atuar nas bibliotecas, na sequência discursiva 'é muito comum encontrar excelentes lideranças no movimento de bibliotecas comunitárias que são analfabetas e defendem a importância de ter neste tipo de organização programas de leitura, contadores de história, formação política etc.', que traz outros sentidos sobre o profissional que tem a preocupação de atuar na formação e manutenção desse espaço. Retomamos, aqui, sentidos já vistos em outros recortes que colocam a atuação nessas bibliotecas ligada não a uma atividade de trabalho, mas de prazer. Temos, ainda, a marcação de uma formação distinta para quem vai usar essas bibliotecas, tais como as ocorrências de 'contadores de história' e 'formação política'. Mesmo com outros sentidos envolvendo esse sujeito, são predicados que o caracterizam e falam de um profissional ligado a luta por melhorias.

Destacamos, por fim, o uso do advérbio de negação ('não') que antecede algumas construções - 'exige uma formação especifica de bibliotecário e com registro no seu respectivo órgão de classe', 'é organizada para gerar emprego', 'tem caráter corporativo' e 'têm diploma de ensino superior' -, marcando as não exigências e as não necessidades 
da instituição comunitária. Por um lado, notamos que o que emerge no discurso do sujeito é o interesse e o desejo para atuar nas bibliotecas, e, ainda, a possibilidade de estabelecer vínculos; por outro lado, a não determinação de exigências tanto no que se refere ao profissional quanto no que diz respeito ao espaço parece atribuir certo desprestígio ao que é discursivizado como comunitário.

\section{Considerações finais}

Diante do exposto, destacamos que as bibliotecas comunitárias permitem novas incursões e sentidos sobre o bibliotecário, pois tem um funcionamento que é quase único dentro das tipologias de instituição existentes no país, dado que, muitas vezes, elas se sustentam sem o auxílio de órgãos governamentais, contando com contribuições de parceiros do Terceiro Setor, empresas, membros da comunidade ou mesmo de cidadãos de outros espaços da sociedade. Desse modo, elas sobrevivem porque há o desejo de uso dos sujeitos das comunidades e o prazer dos profissionais que lá atuam. É, então, por esses motivos que elas conseguem se manter e permanecer fomentando um espaço de leitura e informação na comunidade em que está inserida.

No percurso deste escrito, buscamos compreender, em especial, que sentidos acerca do profissional bibliotecário circulam no bojo dos discursos dos agentes que atuam nos espaços informacionais das suas comunidades. Esse nosso trajeto investigativo repousou, então, sob as bibliotecas comunitárias, instituições formadas e mantidas a partir do desejo de sujeitos que contribuem tanto na construção quanto na constituição desses espaços informacionais. Conforme já apontamos, um fator de relevância para nossas reflexões diz respeito à configuração de muitos desses espaços, que não contam com bibliotecários no quadro de funcionários e, mesmo assim, realizam trabalhos que têm gerado grande impacto nas comunidades em que estão inseridos, como é o caso da Biblioteca BECEI de Paraisópolis, por exemplo, que é, hoje, um espaço atrativo para leitores e turistas brasileiros e estrangeiros.

Nessa perspectiva, os recortes que analisamos colocam em evidência um profissional que, embora em alguns casos não tenha formação específica em biblioteconomia, constitui-se de valores outros e inscreve sentidos também outros, dada sua atuação num espaço singular como a biblioteca comunitária. Retomando as epígrafes de Borges (1975), assinalamos que, assim como cada biblioteca e cada exemplar, o profissional discursivizado em nossos recortes é único, se difere por uma letra ou por uma vírgula, e, ainda com Borges, diríamos, ele é imperfeito, pode ser obra da sorte...

\section{Referências}

ALMEIDA, M. C. B.; MACHADO, E. C. Bibliotecas comunitárias em pauta. São Paulo: Itaú Cultural, 2006. 
BASTOS, G. G. Bibliotecas comunitárias em discurso. 2010. 157f. Trabalho de Conclusão de Curso (Graduação em Ciência da Informação, Documentação e Biblioteconomia) - Faculdade de Filosofia, Ciências e Letras de Ribeirão Preto, Universidade de São Paulo, Ribeirão Preto, 2010.

BASTOS, G. G.; ALMEIDA, M. A.; ROMÃO, L. M. S. Informação \& Sociedade, João Pessoa, v. 21, n. 3, p. 87-100, set./dez. 2011. Disponível em: <http://www.ies.ufpb.br/ojs2/index.php/ies/article/view/10822>. Acesso em: 31 jan. 2012.

BORGES, J. L. A biblioteca de Babel. In: BORGES, J. L. Ficções. 2. ed. São Paulo: Círculo do Livro, 1975. p. 79-89.

FERREIRA, M. C. L. O quadro atual da análise de discurso no Brasil. Revista Letras, Santa Maria, v. 27, n. 2, p. 39-46, jul./dez. 2003. Disponível em: <http://w3.ufsm.br/revistaletras/artigos r27/revista27 3.pdf >. Acesso em: 20 abr. 2011.

FERREIRA, M. C. L. Análise do discurso e suas interfaces: o lugar do sujeito na trama do discurso. Organon, Porto Alegre, v. 24, n. 48, p. 1734, jan./jun. 2010.

INSTITUTO PRÓ-LIVRO. Retratos da leitura no Brasil. São Paulo: Imprensa Oficial, 2008.

LAJOLO, M.; ZILBERMAN, R. A formação da leitura no Brasil. São Paulo: Ática, 2003.

MACHADO, E. C. Bibliotecas comunitárias como prática social no Brasil. 2008. 183f. Teses (Doutorado em Ciência da Informação) - Programa de Pós-Graduação em Ciência da Informação, Universidade de São Paulo, São Paulo, 2008.

MALDIDIER, D. Elementos para uma história da Análise do Discurso na França. In: ORLANDI, E. Gestos de leitura: da história do discurso. Campinas: Editora da Unicamp, 1997. p. 15-25.

MARIANI, B. Subjetividade e imaginário linguístico. Linguagem em (Dis)curso, Tubarão, v. 3, n. esp., p. 55-72, 2003. Disponível em: $<$ http://www3.unisul.br/paginas/ensino/pos/linguagem/0303/6\%20art\%204\%20P.pdf

$>$. Acesso em: 13 jun. 2011.

MICHAELIS: moderno dicionário da língua portuguesa. São Paulo: Melhoramentos, 2009.

MILANO, M. C. D.; DAVOK, D. F. Consultor de informação: serviços prestados por empresas de consultoria nas áreas de Biblioteconomia e Gestão da Informação. Revista ACB: Biblioteconomia em Santa Catarina, Florianópolis, v. 14, n. 1, p. 253-278, jan./jun. 2009. Disponível em: $<$ http://revista.acbsc.org.br/index.php/racb/article/viewArticle/658 >. Acesso em: 13 jun. 2011.

ORLANDI, E. As formas do silêncio: no movimento dos sentidos. Campinas: Editora da UNICAMP, 1997. 
ORLANDI, E. A leitura proposta e os leitores possíveis. In: ORLANDI, E. (Org.). A leitura e os leitores. Campinas: Editora Pontes, 2003.

ORLANDI, E. Michel Pêcheux e a Análise de Discurso. Estudos da Língua(gem), Vitória da Conquista, n. 1, p. 9-13, jun. 2005. Disponível em: <http://www.cpelin.org/estudosdalinguagem/n1jun2005/artigos/orlandi.pdf>. Acesso em: 10 out. 2011.

ORLANDI, E. Análise do discurso: princípios e procedimentos. 8. ed. Campinas: Pontes, 2009.

PACÍFICO, S. M. R.; ROMÃO, L. M. S. A memória e o arquivo produzindo sentidos sobre a trajetória da mulher. Em questão. Porto Alegre, v. 12, n. 1 , p. 73-90, jan./jul. 2006. Disponível em: $<<$ http://www.seer.ufrgs.br/index.php

/EmQuestao./article/viewFile/24/9>>. Acesso: 2 jan. 2012.

SANTOS, J. M. O processo histórico evolutivo das bibliotecas da Antiguidade ao Renascimento. Vida de Ensino, Goiás, v. 1, n. 1, p. 1-10, ago./fev. 2009/2010. Disponível em: <http://rioverde.ifgoiano.edu.br/periodicos/index.php/vidadeensino/articl e/view/58/40>. Acesso em: 21 mar. 2010.

ZOPPI-FONTANA, M. Objetos paradoxais e ideologia. Estudos da Língua(gem), Vitória da Conquista, n. 1, p. 41-59, jun. 2005. Disponível em:

<http://www.estudosdalinguagem.org/n1jun2005/resumos/index_arquivo s/monzoppi.html>. Acesso em: 12 set. 2011. 